Article

\title{
The Effects of Parental Divorce on the Intergenerational Transmission of Crime
}

\section{Steve G.A. van de Weijer ${ }^{1,2, *}$, Terence P. Thornberry ${ }^{3}$, Catrien C.J.H. Bijleveld ${ }^{1,2}$ and} Arjan A.J. Blokland ${ }^{2,4}$

1 Department of Criminal Law and Criminology, VU University, De Boelelaan 1105, Amsterdam 1081 HV, The Netherlands; E-Mail: CBijleveld@nscr.nl

2 Netherlands Institute for the Study of Crime and Law Enforcement (NSCR), PO Box 71304, Amsterdam 1008 BH, The Netherlands; E-Mail: ablokland@nscr.nl

3 Department of Criminology and Criminal Justice, University of Maryland, College Park, MD 20742, USA; E-Mail: thornbet@umd.edu

4 Institute for Criminal Law and Criminology, Leiden University, PO Box 9520, Leiden 2300 RA, The Netherlands

* Author to whom correspondence should be addressed; E-Mail: s.vande.weijer@vu.nl; Tel.: +31-20-59-88628.

Academic Editor: Joanne Savage

Received: 30 May 2014 / Accepted: 27 January 2015 / Published: 10 February 2015

\begin{abstract}
This study first examines the effects of parental divorce and paternal crime on offspring offending. Then, it tests whether parental divorce moderates the intergenerational transmission of crime. Diversity within the offending population is taken into account by examining whether effects are different for fathers who commit crimes at different points of the life-course and by distinguishing between violent and non-violent offending. A sample of 2374 individuals from three consecutive generations from 198 Dutch families was used. The results show that parental divorce increases offspring non-violent offending, but does not increase offspring violence after controlling for parental violence. Moreover, the intergenerational transmission of violence is moderated by parental divorce: empirical evidence for intergenerational transmission of violence is only found for children who did not experience parental divorce during their youth. This moderating effect of parental divorce is even stronger if the father committed violent crimes during the child's youth. The moderating influence of parental divorce on the intergenerational transmission of non-violent crime is less clear, and the effects are overall stronger for violent crime than
\end{abstract}


for non-violent crime. These results suggest that social learning mechanisms play an important role in the intergenerational transmission of violent crime, although genetic influences cannot be ruled out.

Keywords: intergenerational transmission; parental divorce; parental crime; violence; exposure

\section{Introduction}

The family of origin plays an important role in the development of one's criminal behavior, and parent-related factors are important predictors of offending [1,2]. One major parent-related risk factor for criminal development is parental divorce, as several studies have shown that parental divorce leads to offspring antisocial behavior and criminal convictions [3,4]. Another important parent-related risk factor for criminal development that comes forward in the literature is parental criminality. Prospective multigenerational studies have shown that children of criminal parents are at increased risk of becoming criminal themselves [5-7]. One possible explanation for this intergenerational transmission of crime is that children are exposed to their parent's crime and consequently imitate and learn their criminal behavior from them. In case of parental divorce, however, children are likely to be less exposed to their father's criminal behavior, since children usually stay with their mother after a divorce $[8,9]$. The effect of parental crime on offspring offending, therefore, might be different for married and divorced parents. In the current study, data on three consecutive generations of Dutch families are used to examine how parental divorce influences the intergenerational transmission of crime.

There is considerable diversity within the population of offenders that should be taken into account in the assessment of the interaction between parental divorce and parental crime. One dimension concerns violent and non-violent crimes. Violent offenses, including marital violence and child abuse, are probably more often committed at home than non-violent offenses (e.g., theft, burglary, fraud). Moreover, violent crimes may also be a manifestation of an aggressive trait that can also be expressed by aggressive and violent behavior in everyday life. Consequently, children from violent parents might be more likely to witness and learn their parents' repertoire of violent behavior than children from non-violent criminal parents. In support of this assumption, Bernasco [10] showed that assaults are more often committed in the current area of residence of the offender than non-violent crimes, such as residential burglary and theft from cars. In addition, police officers reported that children were present in almost half of the cases of domestic violence [11]. Parental divorce, thus, might decrease exposure to parental violence more than exposure to non-violent parental crimes. Focusing on the moderating effect of parental divorce on the intergenerational transmission of violent crimes might provide more insights into the mechanisms behind this transmission, and therefore, the current study explores whether the moderating effect of parental divorce on the intergenerational transmission of crime is different for violent and non-violent crimes.

A second dimension of diversity concerns the timing of the father's criminal behavior. For example, some offenders are persistently involved in criminal activity over long portions of the life-course while others have relatively short careers, desisting at younger ages [12]. Other patterns have also been 
observed [13]. These varying patterns also influence the potential moderating effects of parental divorce on the intergenerational transmission of crime. For example, the moderating effect may be quite different for careers that begin and end before the birth of the child, as compared to careers that extend into the child's formative years. The present paper assesses both the main effects of parental criminality and divorce, as well as how they may change when offender diversity is considered.

\subsection{Parental Divorce}

In current society, relatively many marriages end up in a divorce, and the proportion of parents who remain married during their children's youth is relatively low. It is, thus, not surprising that a growing volume of research focuses on the consequences of parental divorce for children. This literature has shown that children from one-parent families have a higher risk of dropping out of school, being out of the labor force, becoming pregnant as a teen and having lower psychological well-being than children from two-parent families [3,9,14]. Previous studies further showed, rather consistently, that parental divorce also leads to offspring antisocial and criminal behavior. A meta-analysis by Wells and Rankin [4], for example, showed that delinquency occurs 10 to 15 percent more often among children with divorced parents than among children with married parents. Rodgers and Pryor's [3] meta-analysis even showed that the risk of aggressive behavior, conduct problems, juvenile delinquency and adult criminal behavior is approximately double for children from broken families compared to those from intact families.

This relationship between parental divorce and children's problem behavior is expected from several theoretical perspectives. The transition from a two-parent to a one-parent family might lead to a loss of economic, parental and community resources, according to McLanahan and Sandefur [9]. They argue that one-parent families have fewer economic resources, since there is only one parent in the family to earn an income and fewer expenses can be shared. Moreover, parental divorce is expected to decrease parental resources, as fathers who live in separate households have less contact with their children, which may undermine commitment and trust and lead to less supervision of the child. One-parent families may also have fewer community resources, because families with less income cannot afford to live in communities with better resources and because they move more often. In accordance with this, Amato's [15] meta-analysis showed that several studies indicate that divorced parents invest less time, are less supportive, have fewer rules, dispense hasher discipline, provide less supervision and engage in more conflict with their children, compared with married parents. In addition, Amato [15] refers to several studies that show that post-divorce economic hardship is associated with negative outcomes among children and that events such as moving and changing schools appear to be especially disruptive. These family processes are consistent with several criminological theories, which posit that disruptions to family structure increase both stressors (e.g., poverty, depression) and the chances of ineffective parenting strategies (e.g., low monitoring, harsh discipline), which, in turn, lead to elevated levels of delinquent and criminal behavior [16-19].

The relationship between parental divorce and crime could also be partly spurious. Research among British and Swiss males, for example, showed that children from disrupted families are not at significantly increased risk of being involved in juvenile or adult crime compared to children from intact, but high-conflict families [20,21]. This suggests that it may be the conflictive family situation 
rather than the divorce itself that causes the offspring problem behavior. In addition, Capaldi and Patterson [22] showed that the correlation between mothers' marital transition and their sons' problem behavior can be accounted for by the mothers' antisocial personalities. It is beyond the scope of the current study to test whether the effect of parental divorce on offspring crime is causal or spurious. We only test whether the effect is in the predicted direction, as proposed by both theoretical perspectives and empirical studies.

\subsection{Parental Crime}

Transmission of crime from parents to offspring is expected based on several criminological theories. Farrington [1] distinguished six, not mutually exclusive, mechanisms that may underlay this intergenerational transmission. The first two mechanisms involve risk factors for criminal behavior. First, the intergenerational transmission of crime might be part of a larger cycle of deprivation. According to this explanation, multiple risk factors for criminal development are transmitted across generations leading to an increased risk of criminal behavior in consecutive generations. Second, intergenerational transmission of crime might be moderated by these risk factors for criminal behavior. Criminals tend to live and raise their children in bad neighborhoods, have children at younger ages and use inadequate child-rearing methods. As a consequence, their children are more likely to become criminal. The third mechanism that Farrington [1] distinguished is assortative mating, which points to the finding that criminals tend to live with and mate with criminals from the opposite sex. Children from such criminal couples might be exposed to twice the risk factors for criminal behavior. Fourth, genetic mechanisms might be at work, which indicates that heritable personality traits might be responsible for the criminal behavior of multiple family members. Fifth, the intergenerational transmission of crime might be the consequence of social learning mechanisms if children imitate and learn the criminal behavior from their parents. The sixth and final mechanism, distinguished by Farrington [1], suggests an official bias towards known criminal families. Possibly, law enforcement agencies monitor known criminal families more intensively than unknown criminals, increasing the risk for children of convicted parents to be convicted themselves. Support for each of these mechanisms has been found in different studies with different strengths and weaknesses, which makes it hard to compare which mechanisms explain the intergenerational transmission of crime the best.

In accordance with these mechanisms, several studies have established that crime concentrates within families, as empirical studies from the United States [23,24], England [6] and The Netherlands [25,26] showed that small percentages of families are responsible for a large proportion of all crime committed by samples of families. Moreover, earlier research from prospective multigenerational studies, such as the Cambridge Study in Delinquent Development $[6,27,28]$, the Rochester Youth Development Study [7,29,30], the Criminal Careers and Life-Course Study [31-33] and the Transfive Study [5], provided evidence for the transmission of crime from parents to children and between other family members.

Evidence for transmission of violence has also been found for specific forms of violence, such as child maltreatment [34,35] and intimate partner violence [36]. Convictions for violent crime are also transmitted from father to son [26,37] and between other family members [38]. This intergenerational 
transmission of violent crime has been shown to be larger than the intergenerational transmission of non-violent crime [26].

The timing of parental offending has been shown to influence intergenerational transmission. Van de Rakt and colleagues [33] showed a substantial increase in children's likelihood to be convicted in a year in which their father is also convicted, which indicates that paternal crime has an immediate effect on offspring offending. In addition, Van de Weijer and colleagues [26] showed that paternal violence during the youth of the child increased the risk for offspring to become a violent offender, while no effect was found for paternal violence before birth of the child or during the offspring's adulthood. Besemer [39] also found that parental convictions during the child's youth increased the offspring's conviction rate significantly more than parental convictions before the birth of the child, but this finding did not remain significant after controlling for several risk factors.

\subsection{Moderating Effects}

In order to gain more insight into the mechanisms that are responsible for the intergenerational transmission of (violent) crime, we will examine how this transmission is moderated by parental divorce. Two contrasting ways in which this moderation may work are discussed: accumulation of risk factors and decreased exposure to the criminal parent.

\subsubsection{Cumulating Risk Factors}

First, it is possible that parental divorce increases the odds of children from criminal parents to become criminal. As discussed above, (violent) crime is transmitted between generations, from parent to child [5,6], and children from divorced parents are at increased risk of engaging in criminal behavior [3,4]. Children from disrupted families with a criminal parent are, therefore, exposed to at least two major risk factors for criminal development: a broken family and a criminal parent. Not only may they inherit or learn their parents' criminal behavior, they also may lose economic, parental and community resources or become less attached to their parents due to their parents' divorce. As a consequence, those risk factors may cumulate and further increase the risk for children to become criminal. Since previous research showed that the transmission of violent crimes is larger than that of non-violent crimes [26], it can be expected that this cumulating effect is stronger for children of violent parents compared to those of non-violent criminal parents. Moreover, given that previous research showed that the intergenerational transmission of crime is larger if the parental crime occurs during the child's youth [26], the cumulative effect of parental crime and parental divorce might be stronger for children whose father commits crimes during their youth.

\subsubsection{Decreased Exposure}

In contrast, the relationships among parental divorce, parental criminality and offspring criminality may be more complex than this simple cumulative model suggests. In particular, it can be argued that the intergenerational transmission of crime will be weaker if the parents are divorced. One explanation for this stems from social learning theories, which assume that criminal behavior, as any other behavior, is learned from others [40,41]. Exposure to parental crime, therefore, might lead to children's 
own offending. Since divorce typically means that children remain with their mother $[8,9]$ and, thus, have less contact with their father, they will be less exposed to the behavior of the father. Additionally, of course, paternal criminality is typically the major source of exposure to parent criminality given the large gender imbalance in offending [42]. In the case of a criminal father, the decreased exposure to paternal crime might decrease the degree of social learning. As a consequence, the child is less likely to learn the criminal behavior of his father if his parents are divorced than when they are married. In support of this argument, Blazei, Iacono and McGue [43] showed that the presence of an antisocial father led to externalizing behavior by his children, but the degree of externalizing behavior decreased if the antisocial father were less often present in his children's life. Jaffee and colleagues [44] showed that children living separately from their fathers show more conduct problems if the father engaged in low levels of antisocial behavior, but if the father were highly antisocial, living separately from the father leads to fewer conduct problems. Thornberry and colleagues [30,45] find a significant level of intergenerational continuity in criminal behavior for mothers and for fathers who lived with or had frequent contact with their child, but there was no significant link for fathers with infrequent or no contact with their child. Moreover, Van de Rakt [46] showed that the extent to which parental divorce increases offspring convictions was smaller when the father had been convicted than when the father was never convicted.

These previous studies [30,43-46], however, ignored the diversity within the offender population. First, they focused on antisocial behavior or crime in general and did not differentiate between violent and non-violent crime. For reasons elaborated above, it can be assumed that children's exposure to parental violence is larger than their exposure to non-violent parental crime. Consequently, parental divorce is expected to decrease exposure to parental violence more than exposure to non-violent crimes of the parents. The moderating effect of parental divorce is therefore expected to be larger for the intergenerational transmission of violent crime than for the intergenerational transmission of non-violent crime.

In addition, the previously mentioned studies [30,43-46] also ignored the timing of the antisocial and criminal behavior of the father. In the current study, the timing of the paternal crime is taken into account, because parental divorce can only lead to a decreased exposure to the father's criminal behavior if this paternal crime takes place during the life of the child. Offspring's exposure to paternal crime committed before the birth of the child is impossible, while exposure is less likely if the paternal crime is committed during the child's adulthood when the child is less likely to still live with his parents. Consequently, parental divorce is expected to have the largest influence on the intergenerational transmission of crime when the criminal father commits crimes during the child's youth.

\subsection{The Current Study}

In this study, data on three consecutive generations of Dutch families, comprising persons born between 1917 and 1990 who have been followed from birth until 2007, are used to study the influence of parental divorce and parental crime on offspring criminal behavior. This study contributes to the existing literature by testing whether the intergenerational transmission of crime is moderated by parental divorce. Moreover, it examines whether these moderating effects differ between violent 
criminal fathers and non-violent criminal fathers, as well as when the timing of the father's criminal behavior is taken into account.

\section{Method}

\subsection{Sample}

A sample from the Transfive Study, which contains data on five consecutive generations of Dutch families, was used. The starting point consisted of 198 boys who were placed into a Dutch Catholic reform school between 1911 and 1914. Some boys were placed in this institution because of concern about their character and problem behavior, including minor delinquency. Others were in the reform school because their parents, according to guardian organizations, were not able to take proper care of them. Therefore, these 198 boys can be said to constitute a high-risk sample in terms of delinquency.

The parents and all of the descendants of these boys were traced in Dutch genealogical and municipal records, with a retrieval rate of 100 percent. As the parents of the 198 boys are the oldest generation in the sample, they are called "Generation 1" (G1). The 198 boys are called G2, while their children, grandchildren and great-grandchildren are called G3, G4 and G5, respectively. The G3 to G5 were studied prospectively. On average, the G3 were born in 1932; the G4 in 1960; and the G5 in 1986. At the point of data collection, the surviving G3 were 76 years old, on average. The surviving G4 were about 48 years old and the G5 were 22 years old. Information on all partners was also included in the dataset so that transmission from both parents can be examined. More detailed information can be found in Bijleveld and Wijkman [5].

For the current study, all G4 and G5 who were 18 years or older at the time of data collection and their biological parents are included in the analyses. As a consequence, G4 might be included in the data both as child and as parent. Participants younger than 18 years old were excluded from analysis since individuals in The Netherlands can only be prosecuted from age 12 onwards. By age 18, there was a reasonable exposure time for participants to be convicted of a crime. Participants from the first two generations were excluded from analysis, since the data for these participants were not prospectively collected and were derived from different, and likely less complete, historical archives than the data of the younger three generations. Participants were also excluded from the analysis if they or their parents emigrated from The Netherlands $(N=37)$, because the information on their offending behavior might be truncated. In addition, if one of the parents died during the youth (between age $0-18)$ of the participant $(N=124)$, the participant was excluded from the analysis, because there was less chance to experience parental divorce and the degree of exposure to parental behavior is different from when both parents are alive. For similar reasons, participants whose parents were never married $(N=36)$ were also excluded from the analysis. The final sample consisted of 2374 G4 and G5, and their biological parents. Since the participants in this sample are predominantly ethnic Dutch, Catholic and from families that were part of the lower social strata of Dutch society around the 1900s, they are not representative of the entire Dutch population. 


\subsection{Variables}

The demographic variables for each sample member were obtained from Dutch population registration data (GBA). These data include gender and the dates of birth, death, marriage and divorce. Parental divorce was measured as a dichotomous variable that indicates whether or not a child experienced parental divorce during his or her youth (between ages 0-18).

Information on delinquency was obtained from the archives of the Dutch Criminal Records Documentation Service (“judicial documentation”), in December 2007. Since these records do not contain data on individuals born before 1912 and may miss people born between 1912 and 1916, we have excluded all G3's and their partners born before 1916. The records are complete for the remaining participants, apart for those sample members born in the Almelo "arrondissement" before 1967, which applies to no more than 3\% of the G3 and G4. The registrations that resulted in a conviction were counted. This means that acquittals and so-called "technical dismissals" (i.e., dismissal of a case by the public prosecutor because of insufficient evidence and the case being expected to result in acquittal) were not counted. Cases that never received a disposition or that resulted in a policy dismissal (i.e., dismissal of a case because the prosecutor deemed it unfeasible to prosecute, for instance because the perpetrator had already paid damages) were counted, as they had been registered by the judicial authorities.

Offenses have been classified, based on the "Statistics Netherlands (Centraal Bureau voor de Statistiek) standard classification for offenses" [47]. The violent crimes in this classification include: all hands-on sex crimes (i.e., rape, sexual assault, sexual acts with a minor), crimes against life (i.e., murder and manslaughter), threats, assaults, physical injury, robbery and extortion. All other crimes are considered as non-violent offenses. Offenses were timed to the date the crimes were committed. If the commission date were unknown, it was estimated as one year before the conviction date. If the conviction date were missing, as well, the commission date was timed as 1 July of the year of registration.

The variables indicating the violent behavior of the participants, both offspring and parents, were dichotomized, because they were highly right-skewed: most participants were never convicted of a violent crime, and those who were convicted often only committed one or a couple of offenses. A score of 1 indicates that a participant was ever convicted of at least one violent crime, while a score of 0 indicates that a participant was never convicted of a violent crime. The variables indicating non-violent offending of the participants were constructed in the same way.

\subsection{Analyses}

Logistic regression analysis was first applied to estimate the effects of parental divorce and father's criminal behavior on offspring offending. The use of logistic regression models is necessary, since the dependent variable is binary: whether or not the child was ever convicted. In order to test whether the intergenerational transmission of crime is moderated by parental divorce, the children were divided into those who experienced parental divorce during their youth and those who did not. For these two groups of children, separate logistic regression models were applied to estimate the effects of the father's criminal behavior on offspring criminal behavior. Finally, we examined whether the 
moderating effect of parental divorce on the intergenerational transmission of crime differed between different types of criminal fathers. This was first done by taking into account the timing of the paternal crime(s). Criminal fathers who committed crimes during their child's youth (0-18 year) were distinguished from criminal fathers who did not commit crimes during their child's youth (i.e., these fathers only committed crimes before the birth of the child or during the child's adulthood). Separate logistic regression models were estimated in which children with these types of fathers were compared to children with non-offending fathers. Second, all analyses were done separately for violent and non-violent crime in order to examine whether parental divorce influences the intergenerational transmission of violent crime differently than the intergenerational transmission of non-violent crime. In order to compare the effects of having a violent father with non-offending fathers, all fathers who were convicted, but not for (a) violent crime(s), and their children, were excluded from the analyses that focus on violent crime. For the same reason, all fathers who only committed (a) violent crime(s), and their children, were excluded from the analyses that focus on non-violent crime. In all logistic regression analyses, child's sex, child's age (at the time of data collection), child's age squared and the criminal behavior of the mother were included as control variables. Child's age squared was included as a control variable, as age and offending have a curvilinear relationship.

Since the sample includes multiple children from the same father, the assumption of independence among observations is violated. To control for this intra-cluster correlation, generalized estimation equations (GEE models) were used to estimate the logistic regression models [48]. GEE models ignore the correlations between repeated measures within the same family and correct the standard errors of regression coefficients by estimating robust standard errors. Moreover, all GEE models were estimated separately for G3-fathers and their G4-children and for G4-fathers and their G5-children, so that the G4-men are not included in the same regression model, both as father and as child. In order to examine whether odds ratios from different logistic regression models are significantly different from each other, a ratio of odds ratios (ROR) with corresponding confidence intervals was calculated [49]. The significance of those RORs, however, should be interpreted with some caution, as there is dependence between the samples compared.

\section{Results}

\subsection{Descriptives}

The upper part of Table 1 presents the range, mean and standard deviation of the scores of all variables that were used in the analyses for violent crime, separately for G3-G4 and G4-G5. The average age of the participants is about 47 years for the G4-children and 28 years for the G5-children. About half of the participants is male, and only a very small proportion of the mothers was ever convicted of a violent crime. Among the G4-children, 15 percent experienced parental divorce during their youth, while 27 percent of the G5-children experienced parental divorce during their youth. This increasing rate of parental divorce across generations is not surprising, given the increasing divorce rates in The Netherlands between 1950 and 2000 [50]. Table 1 further shows that 24 percent of the G4-children have a G3-father who was convicted of a violent crime, while 21 percent of the G5-children have a violent G4-father. For both generations, about half of the violent fathers committed 
their violent crimes during the youth of the child, while the other half of the violent fathers was not convicted of a violent crime during the youth of the child. Descriptives of the dependent variable show that eight percent of the G4-children and six percent of the G5-children were ever convicted of a violent crime. This small decrease of violent offenders across generations is probably the consequence of the fact that the G5-children are younger and, thus, had less time to be convicted of a violent crime. In the analyses for violent crime, 661 G4-children and 609 G5-children were included in the sample.

Table 1. Descriptives.

\begin{tabular}{|c|c|c|c|c|c|c|}
\hline \multirow{2}{*}{ Variables } & \multicolumn{3}{|c|}{ G3-G4 } & \multicolumn{3}{|c|}{ G4-G5 } \\
\hline & Range & Mean & SD & Range & Mean & SD \\
\hline \multicolumn{7}{|c|}{ Analyses for Violent Crime } \\
\hline \multicolumn{7}{|l|}{ Control variables } \\
\hline Age of child & 18.81-79.05 & 47.59 & 9.22 & $18.02-55.32$ & 28.04 & 6.94 \\
\hline Sex (1 = male) & $0-1$ & 0.49 & 0.50 & $0-1$ & 0.53 & 0.50 \\
\hline Violent mother & $0-1$ & 0.03 & 0.17 & $0-1$ & 0.01 & 0.11 \\
\hline \multicolumn{7}{|l|}{ Independent variables } \\
\hline Parental divorce & $0-1$ & 0.15 & 0.35 & $0-1$ & 0.27 & 0.44 \\
\hline Violent father & $0-1$ & 0.24 & 0.43 & $0-1$ & 0.21 & 0.40 \\
\hline \multicolumn{7}{|l|}{ Timing of paternal violence } \\
\hline Violent, but not during youth of child & $0-1$ & 0.13 & 0.33 & $0-1$ & 0.09 & 0.28 \\
\hline Violent during youth of child & $0-1$ & 0.11 & 0.31 & $0-1$ & 0.12 & 0.32 \\
\hline \multicolumn{7}{|l|}{ Dependent variable } \\
\hline Violent child & $0-1$ & 0.08 & 0.28 & $0-1$ & 0.06 & 0.24 \\
\hline$N$ & 661 & & & 609 & & \\
\hline \multicolumn{7}{|c|}{ Analyses for Non-Violent Crime } \\
\hline \multicolumn{7}{|l|}{ Control variables } \\
\hline Age of child & 18.32-79.05 & 47.44 & 9.21 & $18.02-55.32$ & 28.28 & 7.16 \\
\hline Sex $(1=$ male $)$ & $0-1$ & 0.51 & 0.50 & $0-1$ & 0.53 & 0.50 \\
\hline Non-violent criminal mother & $0-1$ & 0.23 & 0.42 & $0-1$ & 0.18 & 0.39 \\
\hline \multicolumn{7}{|l|}{ Independent variables } \\
\hline Parental divorce & $0-1$ & 0.15 & 0.35 & $0-1$ & 0.29 & 0.45 \\
\hline Non-violent criminal father & $0-1$ & 0.52 & 0.50 & $0-1$ & 0.53 & 0.50 \\
\hline \multicolumn{7}{|l|}{ Timing of paternal crime } \\
\hline Non-violent, but not during youth of child & $0-1$ & 0.26 & 0.44 & $0-1$ & 0.18 & 0.39 \\
\hline Non-violent during youth of child & $0-1$ & 0.26 & 0.44 & $0-1$ & 0.35 & 0.48 \\
\hline \multicolumn{7}{|l|}{ Dependent variable } \\
\hline Non-violent criminal child & $0-1$ & 0.37 & 0.48 & $0-1$ & 0.27 & 0.44 \\
\hline$N$ & 1054 & & & 1039 & & \\
\hline
\end{tabular}

The lower part of Table 1 presents the range, mean and standard deviation of the scores of all variables used in the analyses for non-violent crime, again separately for G3-G4 and G4-G5. The descriptives of age, sex and parental divorce are similar to those in the upper part of Table 1 . The non-violent offending rates of the mothers, fathers and children are, however, larger than the violent offending rates. More than half of the G4-children and G5-children have a non-violent criminal father. Among the G4-children, half of these non-violent offending G3-fathers committed their crimes during 
the youth of their child, while the other half did not. Among the non-violent offending G4-fathers, about two thirds committed their crimes during the youth of their G5-children, while the remaining third did not. The offending rates of the children are again larger for the G4-children (37 percent) than for the G5-children (27 percent). In the analyses for non-violent crime, 1054 G4-children and 1039 G5-children were included in the sample.

\subsection{Main Effects of Parental Divorce and Parental Crime}

In Table 2, the results from the GEE-models are shown in which the main effects of parental divorce and paternal crime on offspring offending are estimated. The upper part of Table 2 shows the results for violent offending. Model 1 and Model 2 show that both paternal violence and parental divorce have a significant positive effect on offspring violence, for both G3-G4 and G4-G5. These results indicate that participants with a violent father and participants whose parents divorced during their youth are more likely to be convicted of a violent crime. However, when both risk factors are included in the same model, the significant effect of parental divorce disappears. The effect of paternal violence decreases slightly after including parental divorce in the model, but remains significant.

Table 2. Generalized estimation equation (GEE) models for the impact of paternal crime and parental divorce on offspring offending.

\begin{tabular}{|c|c|c|c|}
\hline \multirow{2}{*}{ Variables } & Model 1 & Model 2 & Model 3 \\
\hline & Odds Ratio (CI) & Odds Ratio (CI) & Odds Ratio (CI) \\
\hline \multicolumn{4}{|c|}{ Violent Crime } \\
\hline \multicolumn{4}{|l|}{ G3-G4 } \\
\hline Paternal violence & $2.55(1.38-4.72)$ & & $2.32(1.23-4.35)$ \\
\hline Parental divorce & & $2.22(1.09-4.53)$ & $1.85(0.88-3.86)$ \\
\hline \multicolumn{4}{|l|}{ G4-G5 } \\
\hline Paternal violence & $4.49(2.14-9.38)$ & & $3.39(1.52-7.52)$ \\
\hline Parental divorce & & $3.11(1.53-6.32)$ & $2.06(0.95-4.46)$ \\
\hline \multicolumn{4}{|c|}{ Non-Violent crime } \\
\hline \multicolumn{4}{|l|}{ G3-G4 } \\
\hline Paternal non-violent crime & $1.28(0.97-1.68)$ & & $1.24(0.94-1.63)$ \\
\hline $\begin{array}{c}\text { Parental divorce } \\
\text { G4-G5 }\end{array}$ & & $1.53(1.04-2.25)$ & $1.48(1.00-2.18)$ \\
\hline Paternal non-violent crime & $1.99(1.45-2.73)$ & & $1.88(1.37-2.59)$ \\
\hline Parental divorce & & $1.75(1.25-2.44)$ & $1.60(1.14-2.25)$ \\
\hline
\end{tabular}

Note: All odds ratios are controlled for age, age squared, sex and maternal offending; significant odds ratios are in bold.

The lower part of Table 2 shows the results for non-violent offending. Model 1 shows that a significant effect of non-violent paternal offending is found for G4-G5, but not for G3-G4. Intergenerational transmission of non-violent crime is thus only found for the younger generations. The effects of parental divorce on offspring non-violent offending, as shown in Model 2, are significant for both G3-G4 and G4-G5 and indicate that participants who experienced parental divorce during their youth are more likely to be convicted of a non-violent crime. Both risk factors are 
included in Model 3. Although the odds ratios become slightly smaller, the significance of variables does not change compared to Models 1 and 2.

\subsection{Moderating Effect of Parental Divorce}

Next, we examined whether parental divorce moderates the intergenerational transmission of crime. In Table 3, odds ratios indicating the intergenerational transmission of violent and non-violent crime are shown, separately for participants who experienced parental divorce during their youth and those who did not. The results indicate that significant intergenerational transmission of violent crime is only found among participants whose parents did not divorce during their youth (OR G3-G4: 2.51 (1.28-4.92); OR G4-G5: 5.01 (1.65-15.23)). The participants who did experience parental divorce, on the other hand, were not at increased risk of becoming a violent offender if their fathers were convicted of a violent crime (OR G3-G4: 1.61 (0.50-5.17); OR G4-G5: 2.43 (0.80-7.34)). These results were found for both the older (G3-G4) and the younger (G4-G5) generations. Ratios between odds ratios (RORs) were estimated to test whether the odds ratio of participants who experienced parental divorce were significantly different from those who did not experience parental divorce. These RORs were, however, neither significant for G3-G4 (ROR: 1.56 (0.40-6.00)) nor for G4-G5 (ROR: 2.06 (0.43-9.90)). This might be the consequence of the relatively low number of violent participants, which leads to large confidence intervals in the odds ratios.

Table 3. GEE models for intergenerational transmission of crime, split by marital status of the parents.

\begin{tabular}{ccccc}
\hline Generation & \multicolumn{2}{c}{ G3-G4 } & \multicolumn{2}{c}{ G4-G5 } \\
\hline Parental divorce & Not divorced & Divorced & Not divorced & Divorced \\
\hline Violent crime & $\mathbf{2 . 5 1}(\mathbf{1 . 2 8}-\mathbf{4 . 9 2})$ & $1.61(0.50-5.17)$ & $\mathbf{5 . 0 1}(\mathbf{1 . 6 5 - 1 5 . 2 3 )}$ & $2.43(0.80-7.34)$ \\
Non-violent crime & $1.31(0.97-1.77)$ & $1.02(0.48-2.16)$ & $\mathbf{1 . 7 7}(\mathbf{1 . 2 1}-\mathbf{2 . 5 9})$ & $\mathbf{2 . 2 7}(\mathbf{1 . 2 5}-\mathbf{4 . 1 5})$ \\
\hline
\end{tabular}

Note: All odds ratios are controlled for age, age squared, sex and maternal offending, if possible. In the analyses regarding violent crime with G4-children with divorced parents, it was only possible to control for age and age squared; significant odds ratios are in bold.

The results regarding the intergenerational transmission of non-violent crime are somewhat different. Among G3-G4, significant odds ratios were not found for participants who experienced parental divorce (OR: 1.02 (0.48-2.16)) or for those who did not (OR: 1.31 (0.97-1.77)). Among G4-G5, significant intergenerational transmission of non-violent crime was found for both participants who did not experience parental divorce (OR: 1.77 (1.21-2.59)), as well as for those who did experience parental divorce (OR: 2.27 (1.25-4.15)). Again, no significant RORs were found (ROR G3-G4: 1.28 (0.57-2.89); ROR G4-G5: 0.78 (0.38-1.59)), which is not surprising, given the small differences between the odds ratios.

\subsection{Timing of Parental Crime}

In the final analyses, the timing of the paternal crime is taken into account by examining the influence of parental divorce on the intergenerational transmission of crime for offenders who committed crimes during the youth of their child and those who did not. The upper part of Table 4 
shows the results for the former group of offenders. The odds ratio for G3-G4 (4.22 (1.86-9.56)) shows that G4-children who did not experience parental divorce had significantly higher odds of becoming a violent offender if their G3-father committed violent crimes during their youth. This effect was not found for G4-children with divorced parents (OR: 1.23 (0.31-4.88)). Among the G5-children, both children who did not experience parental divorce and those who did experience parental divorce were significantly more likely to become a violent offender if their G4-father committed violent crimes during their youth. The odds ratio for G4-children with parents who remained married (13.33 (2.67-66.49)) is, however, much higher than the odds ratio for G4-children with divorced parents (3.17 (1.07-9.41)). These results indicate that the moderating influence of parental divorce on the intergenerational transmission of violent crime is larger if the father committed violent crimes during the youth of the child. Although the odds ratios are about four times as large for children who did not experience parental divorce compared to those who did, the difference between the odds ratios is neither significant for G3-G4 (ROR: 3.43 (0.69-17.04)) nor for G4-G5 (ROR: 4.21 (0.60-29.28)). This is likely the consequence of the low number of violent offenders in the sample, which results in large confidence intervals.

Table 4. GEE models for intergenerational transmission of crime, split by marital status of the parents and the type of father.

\begin{tabular}{|c|c|c|c|c|}
\hline \multirow{2}{*}{$\begin{array}{c}\text { Generation } \\
\text { Parental divorce }\end{array}$} & \multicolumn{2}{|c|}{ G3-G4 } & \multicolumn{2}{|c|}{ G4-G5 } \\
\hline & Not divorced & Divorced & Not divorced & Divorced \\
\hline \multicolumn{5}{|c|}{ Father Offends during Youth Child } \\
\hline Violent crime & $4.22(1.86-9.56)$ & $1.23(0.31-4.88)$ & $13.33(2.67-66.49)$ & $3.17(1.07-9.41)$ \\
\hline Non-violent crime & $1.50(1.03-2.19)$ & $1.07(0.47-2.46)$ & $1.62(1.04-2.53)$ & $2.41(1.30-4.46)$ \\
\hline \multicolumn{5}{|c|}{ Father does not offend during youth child } \\
\hline Violent c & $1.53(0.60-3.90)$ & $2.47(0.57-10.72)$ & $3.04(0.77-11.99)$ & $a$ \\
\hline Non-violent crime & $1.19(0.83-1.71)$ & $1.05(0.40-2.80)$ & $2.05(1.27-3.32)$ & $2.18(0.77-6.14)$ \\
\hline
\end{tabular}

Note: $a$, this odds ratio could not be estimated, since none of the eight children with a violent father in this group were convicted of a violent crime; all odds ratios are controlled for age, age squared, sex and offending, if possible. In the analyses regarding violent crime with G4-children with divorced parents, it was only possible to control for age and age squared; significant odds ratios are in bold.

Concerning non-violent crimes, the upper part of Table 4 shows that G4-children who did not experience parental divorce were also at increased risk of becoming non-violent offenders if their G3-father committed a non-violent crime during their youth (OR: 1.50 (1.03-2.19)), while this effect was not found for G4-children with divorced parents (OR: 1.07 (0.47-2.46)). Among the G5-children, odds ratios were significant for both those with married (OR: 1.62 (1.04-2.53)) and divorced parents (OR: 2.41 (1.30-4.46)). Remarkably, the odds ratio for the latter group is larger than for the former group. However, the difference between the odds ratios is small and not significant for G3-G4 (ROR: 1.40 (0.56-3.48)) nor for G4-G5 (ROR: 0.67 (0.31-1.44)).

The lower part of Table 4 shows the results for criminal fathers who did not commit their crimes during the child's youth. None of the odds ratios for violent crime are significant, indicating that there is no intergenerational transmission of violent crime if the father did not commit violent crimes during the youth of his child, regardless of whether the parents were divorced or not. The moderating 
influence of parental divorce on the intergenerational transmission of violent crime is thus not found in families with this type of violent father. Concerning non-violent crime, a significant effect was only found for G5-children who did not experience parental divorce. The odds ratio of 2.05 (1.27-3.32) indicates that these G5-children are at increased risk of committing a non-violent offense if their G4-father were convicted of a non-violent offense, even though this offense was not committed during their youth. This odds ratio was not significant for G5-children with divorced parents (OR: 2.18 (0.77-6.14)). The difference between these two odds ratios is small and not significant (ROR: 0.94 (0.30-2.95)). Overall, the odds ratios, for both violent and non-violent crime, in Table 4 are generally larger and more often significant if the father committed his crimes during the youth of the child, than when the criminal father was not convicted during the youth of the child.

\section{Conclusion}

In this study, conviction data on 2374 individuals from three consecutive generations are used to examine the effects of parental divorce and parental crime on offspring offending behavior. In addition, the moderating influence of parental divorce on the intergenerational transmission of crime is examined in order to better understand the mechanisms behind this transmission. Diversity within the group of offenders is taken into account by separately examining violent and non-violent offenders, as well as by taking into account the timing of paternal crime.

The results show that the participants are more likely to become a violent offender when they experienced parental divorce during their youth or when they have a violently offending father. However, when both risk factors are included in the same model, parental divorce does not have a significant influence on offspring violence anymore, while the effect of paternal violence remains significant. This finding seems in line with the results of Capaldi and Patterson [22], who found that the relationship between parental divorce and offspring offending can be accounted for by parental antisocial personalities. However, the effect of parental divorce on non-violent offending remained significant after controlling for parental non-violent offending. A possible explanation for the finding that parental divorce leads to the offspring's non-violent offending, but not violent offending might be the economic hardship that children of divorced parents experience. This might lead to property crimes committed by children of divorced parents to compensate for the decreased economic resources. These results underline the importance of distinguishing between different types of crime when studying the negative influences of parental divorce.

A moderating influence of parental divorce on the intergenerational transmission of violent crime was also found, which is in line with earlier research [30,43-46] that found similar interaction effects between parental divorce or absence and parental offending or antisocial behavior. The results showed that intergenerational transmission of violent crime only occurred if the violent father remained married to the mother during the youth of the child. When children of violent fathers experienced parental divorce during their youth, violent offending was not transmitted. Given the fact that children usually remain with their mother after parental divorce [8,9], it is reasonable to assume that children of divorced parents are less exposed to the (violent) behavior of their fathers than children of married parents. The finding that intergenerational transmission of violent crime only occurs among those with married parents therefore suggests that exposure to (the consequences of the) violent behavior of the 
father plays an important role in this intergenerational transmission. These results, therefore, seem in line with social learning theories [40,41].

The final analyses, in which the timing of the paternal violence is taken into account, similarly suggest that exposure to a violent father plays an important role in the intergenerational transmission of violent crime. If the father engaged in violent crime during his offspring's childhood, the moderating influence of parental divorce on the intergenerational transmission of crime was even larger. The intergenerational transmission of violence from these fathers was about four-times as large if the father remained married during the youth of the child as when he was divorced. On the other hand, if the father did not commit his violent crime(s) during the youth of the child, no intergenerational transmission was found, regardless of the marital status of the parents. In these cases, offspring's exposure to the paternal violence is impossible (if committed before the child's birth) or less likely (if committed during the child's adulthood), which may explain why no intergenerational transmission was found.

These results further show that the intergenerational transmission of violence cannot (completely) be accounted for by genetic influences, since a moderating influence of parental divorce and the timing of the paternal violence would be unlikely in that case. A role for genetics should, however, not be ruled out. Biosocial criminologists emphasize that biological and social factors interact with each other. It might, for example, be possible that individuals who are genetically predisposed to violent offending only actually commit violent crimes after they have been exposed to, or victimized by, violent crime. It would be desirable if future studies further investigated the precise mechanisms behind the intergenerational transmission of violent crime.

The results regarding the intergenerational transmission of non-violent crime were different from those regarding violent crime. Among the older generations, no intergenerational transmission of non-violent crime was found, regardless of the marital status of the parents. Among the younger generations, on the other hand, the intergenerational transmission of non-violent crime was larger if the parents were divorced. These results suggest that the effect of parental divorce and paternal non-violent crime on offspring non-violent offending may be cumulative. Results further showed that, if parents remain married, having a non-violent criminal father who did not offend during the child's youth still increases the risk of the offspring becoming a non-violent offender. This suggests that exposure to paternal crime and social learning mechanisms play a less important role in explaining the intergenerational transmission of non-violent crime. A possible explanation for this might be that violent crimes are more often committed at home than non-violent crimes.

\subsection{Limitations and Strengths}

As any other study, this study is limited in several ways. The first and most important limitation of this study is the lack of information on the addresses of the participants and their parents. Consequently, it is not known for sure whether the child remained with the mother in cases of parental divorce. However, until 1998, Dutch children of divorced parents automatically stayed with their main caregiver (almost always the mother), and visits were arranged with the non-residential parent (almost always the father). After a change in legislation in 1998, both parents automatically have joint custody of the children after a divorce [51]. In 2001, however, 80 percent of the Dutch children with divorced 
parents still lived with their mother, while only 15 percent lived with their father and a small percentage lived alternately with one of the parents [8]. Children with a criminal or violent father are expected to be even more likely to live with their mother, since she is more likely to receive custody of the child due to court decisions. In addition, De Graaf [52] showed that a quarter of the children of divorced parents in the Dutch population did not have any contact with their non-residential father anymore, while another quarter had poor contact with their non-residential father. Although it, thus, can be assumed that a very large share of the children with divorced parents live with their mother and have reduced contact with their fathers, results should be interpreted with some caution.

A second limitation is that we had to rely on official sources for the data on offending behavior. Much (violent) crime is not captured by these official statistics. Consequently, it is quite possible that some children in the sample do have violent or criminal parents, but that these parents were never convicted of a crime. Moreover, the two types of offenders that were distinguished based on the timing of their offenses might have been different if all crimes that had actually been committed were taken into account. Another disadvantage of the underestimation of actual criminal behavior by the official statistics is the low number of violent offenders. Especially after splitting up between different generations and parent's marital status, the number of violent offenders in groups became low, and the statistical power of the analyses was relatively low. Consequently, the odds ratios, both significant and insignificant ones, have wide confidence intervals, which made it hard to find statistically-significant differences between odds ratios, even when there were large absolute differences between them. The relatively low number of violent offenders, according to conviction data, also made it impossible to distinguish between paternal violence committed during different periods within the child's youth (e.g., infancy, childhood, adolescence). Very young children (e.g., 0-1 years old) are unlikely to imitate and learn violent behavior. The observed relationships therefore might have been stronger if only older ages, at which the children are more likely to observe and imitate their father's violent behavior, were taken into account. In addition, it was not possible to distinguish between fathers who committed violent crimes prior to their divorce and fathers who committed violent crimes after their divorce. Based on social learning theories, stronger intergenerational transmission of violence would be expected among the former group than among the latter group, since children whose father committed violent crimes before the divorce are more likely to be exposed to this violence. The use of conviction data, thus, might have decreased the strength of the relationships found, and our results should therefore, again, be interpreted with some caution.

A final limitation is that information on a number of potential confounders was not available due to the fact that only official data are used. Potential confounding factors, such as psychopathy, self-control and unemployment, might have an (indirect) influence on both divorce and offspring offending, but could not be taken into account in the analyses. The effects of genetic factors could have been taken into account by comparing pairs of relatives who differ on the level of genetic similarity. This, however, would have required a very different type of analysis and is beyond the scope of the current study. Despite these limitations, our study has several strengths. A large dataset was used with prospectively collected data on the offending behavior of persons from three consecutive generations who have been followed over a large part of the life-course, well into adulthood. Furthermore, this study is among the first to examine the moderating influence of parental divorce on the intergenerational transmission of crime. In addition, the influence of parental divorce on the intergenerational 
transmission of both violent and non-violent crime was studied, while most previous studies focused on antisocial behavior or crime in general. Finally, this study demonstrated the importance of taking into account the diversity in the offender population when examining the effects of parental divorce and parental crime on offspring crime, since the results showed that these effects differ between fathers who commit crimes during different periods over the life-course.

\subsection{Implications}

For future research, these results underline the importance of examining conditional effects, as it is shown that the degree of intergenerational transmission of crime is different for children with married parents and children with divorced parents. It would be an interesting topic for future studies to examine whether other life events that decrease day-to-day exposure to the father (e.g., paternal death, paternal imprisonment, conscription, employment abroad) affect the transmission of violent crime from father to child. Moreover, it is recommended for future research to address diversity within the offender population. As this study showed that the effects of parental divorce and parental offending on offspring offending differed between different groups of offending fathers, it is important to take into account the timing and type of parental offending when studying the intergenerational transmission of crime.

Finally, the results from this study reveal some practical implications. As this study showed, consistent with previous research, parental divorce and parental crime in general are risk factors for offspring offending. The consistency of this finding across studies highlights the necessity of providing additional services to children from intact families where the father has a criminal, especially a violent criminal, record. Those children are at elevated risk for offending and need to be protected especially when they are exposed to the violent behavior of the father or when the children start to show (violent) offending behavior themselves.

\section{Acknowledgments}

The authors acknowledge financial support from Stichting Pro Musis, Hesseveld Stichting, Broedercongregatie Onze Lieve Vrouw Van Zeven Smarten, Aloysius Stichting, Expertisecentrum Rechtshandhaving Ministry of Justice and The Netherlands Organisation for Scientific Research (Nederlandse Organisatie voor Wetenschappelijk Onderzoek) Grant 400-08-039.

\section{Author Contributions}

Steve van de Weijer performed the statistical analyses and drafted the manuscript. Terence Thornberry, Catrien Bijleveld and Arjan Blokland provided constructive feedback on drafts of the manuscript.

\section{Conflicts of Interest}

The authors declare no conflict of interest. 


\section{References}

1. Farrington, D.P. Families and crime. In Crime and Public Policy; Wilson, J.Q., Petersilia, J., Eds.; Oxford University Press: New York, NY, USA, 2011; pp. 130-157.

2. Thornberry, T.P.; Krohn, M.D. Taking Stock of Delinquency: An Overview of Findings from Contemporary Longitudinal Studies; Kluwer Academic Publishers: New York, NY, USA, 2003.

3. Rodgers, B.; Pryor, J. Divorce and Separation: The Outcomes for Children; Joseph Rowntree Foundation: York, UK, 1998.

4. Wells, L.E.; Rankin, J.H. Families and delinquency: A meta-analysis of the impact of broken homes. Soc. Probl. 1991, 38, 71-93.

5. Bijleveld, C.C.J.H.; Wijkman, M.D.S. Intergenerational continuity in convictions: A five-generation study. Crim. Behav. Ment. Health 2009, 19, 142-155.

6. Farrington, D.P.; Barnes, G.C.; Lambert, S. The concentration of offending in families. Leg. Criminol. Psychol. 1996, 1, 47-63.

7. Thornberry, T.P. The apple doesn't fall far from the tree (or does it?): Intergenerational patters of antisocial behavior-The American Society of Criminology 2008 Sutherland Address. Criminology 2009, 47, 297-325.

8. De Graaf, A. Ervaringen van kinderen met het ouderlijk gezin. Maandstat. Bevolk. 2001, 49, 12-15.

9. McLanahan, S.; Sandefur, G. Growing up with a Single Parent: What Hurts, What Helps; Harvard University Press: Cambridge, MA, USA, 1994.

10. Bernasco, W. A sentimental journey to crime: Effects of residential history on crime location choice. Criminology 2010, 48, 389-416.

11. Fantuzzo, J.W.; Fusco, R.A. Children's direct exposure to types of domestic violence crime: A population-based investigation. J. Fam. Violence 2007, 22, 543-552.

12. Moffitt, T.E. Adolescence-limited and life-course-persistent antisocial behavior: A developmental taxonomy. Psychol. Rev. 1993, 100, 674-701.

13. Piquero, A.R. Taking stock of developmental trajectories of criminal activity over the life course. In The Long View of Crime: A Synthesis of Longitudinal Research; Liberman, A.M., Ed.; Springer: New York, NY, USA, 2008; pp. 23-78.

14. Amato, P.R. Children of divorce in the 1990s: An update of the Amato and Keith (1991) meta-analysis. J. Fam. Psychol. 2001, 15, 355-370.

15. Amato, P.R. The consequences of divorce for adults and children. J. Marriage Fam. 2000, 62, 1269-1287.

16. Catalano, R.F.; Hawkins, J.D. A social development model: A theory of antisocial behavior. In Delinquency and Crime; Hawkins, J.D., Ed.; Cambridge University Press: New York, NY, USA, 1996; pp. 149-197.

17. Patterson, G.R.; Reid, J.B.; Dishion, T.J. Antisocial Boys: A social interactional approach; Castalia Press: Eugene, OR, USA, 1992.

18. Sampson, R.J.; Laub, J.H. Crime in the Making: Pathways and Turning Points through Life; Harvard University Press: Cambridge, MA, USA, 1993.

19. Thornberry, T.P. Toward an interactional theory of delinquency. Criminology 1987, 25, 863-892. 
20. Haas, H.; Farrington, D.P.; Killias, M.; Sattar, G. The impact of different family configurations on delinquency. Br. J. Criminol. 2004, 44, 520-532.

21. Juby, H.; Farrington, D.P. Disentangling the link between disrupted families and delinquency. Br. J. Criminol. 2001, 41, 22-40.

22. Capaldi, D.M.; Patterson, G.R. Relation of parental transitions to boy's adjustmentproblems: I. A linear hypothesis. II. Mothers at risk for transitions and unskilled parenting. Dev. Psychol. 1991, 27, 489-504.

23. Farrington, D.P.; Jolliffe, D.; Loeber, R.; Stouthamer-Loeber, M.; Kalb, L.M. The concentration of offenders in families, and family criminality in the prediction of boys' delinquency. J. Adolesc. 2001, 24, 579-596.

24. Beaver, K.M. The familial concentration and transmission of crime. Crim. Justice Behav. 2013, 40, 139-155.

25. Junger, M.; Greene, J.; Schipper, R.; Hesper, F.; Estourgie, V. Parental criminality, family violence and intergenerational transmission of crime within a birth cohort. Eur. J. Crim. Policy Res. 2013, 19, 1-17.

26. Van de Weijer, S.G.A.; Bijleveld, C.C.J.H.; Blokland, A.A.J. The intergenerational transmission of violent offending. J. Fam. Violence 2014, 29, 109-118.

27. Farrington, D.P.; Coid, J.W.; Murray, J. Family factors in the intergenerational transmission of offending. Crim. Behav. Ment. Health 2009, 19, 109-124.

28. Rowe, D.C.; Farrington, D.P. The familial transmission of criminal convictions. Criminology 1997, 35, 177-201.

29. Thornberry, T.P.; Freeman-Gallant, A.; Lizotte, A.J.; Krohn, M.D.; Smith, C.A. Linked lives: The intergenerational transmission of antisocial behavior. J. Abnorm. Child Psychol. 2003, 31, 171-184.

30. Thornberry, T.P.; Freeman-Gallant, A.; Lovegrove, P.J. Intergenerational linkages in antisocial behaviour. Crim. Behav. Ment. Health 2009, 19, 80-93.

31. Van de Rakt, M.; Nieuwbeerta, P.; Apel, R. Association of criminal convictions between family members: Effects of siblings, fathers and mothers. Crim. Behav. Ment. Health 2009, 19, 94-108.

32. Van de Rakt, M.; Nieuwbeerta, P.; de Graaf, N.D. Like father, like son. The relationships between conviction trajectories of fathers and their sons and daughters. Br. J. Criminol. 2008, 48, 538-556.

33. Van de Rakt, M.; Ruiter, S.; de Graaf, N.D.; Nieuwbeerta, P. When does the apple fall from the tree? Static versus dynamic theories predicting intergenerational transmission of convictions. J. Quant. Criminol. 2010, 26, 371-389.

34. Berlin, L.J.; Appleyard, K.; Dodge, K.A. Intergenerational continuity in child maltreatment: Mediating mechanisms and implications for prevention. Child Dev. 2011, 82, 162-176.

35. Thornberry, T.P.; Henry, K.L. Intergenerational continuity in maltreatment. J. Abnorm. Child Psychol. 2013, 41, 555-569.

36. Smith, C.A.; Ireland, T.O.; Park, A.; Elwyn, L.; Thornberry, T.P. Intergenerational continuities and discontinuities in intimate partner violence: A two-generational prospective study. J. Interpers. Violence 2011, 26, 3720-3752. 
37. Besemer, S. Specialised versus versatile intergenerational transmission of violence: A new approach to studying intergenerational transmission from violent versus non-violent fathers: Latent Class Analysis. J. Quant. Criminol. 2012, 28, 245-263.

38. Frisell, T.; Lichtenstein, P.; Långström, N. Violent crime runs in families: A total population study of 12.5 million individuals. Psychol. Med. 2011, 41, 97-105.

39. Besemer, S. The impact of timing and frequency of parental criminal behaviour and risk factors on offspring offending. Psychol. Crime Law 2014, 20, 78-99.

40. Akers, R.L. Deviant Behavior: A Social Learning Approach; Wadsworth: Belmond, CA, USA, 1997.

41. Bandura, A. Social Learning Theory; Prentice-Hall: Englewood Cliffs, NJ, USA, 1977.

42. Moffitt, T.E.; Caspi, A.; Rutter, M.; Silva, P.A. Sex Differences in Antisocial Behavior: Conduct Disorder, Delinquency, and Violence in the Dunedin Longitudinal Study; Cambridge University Press: Cambridge, UK, 2001.

43. Blazei, R.W.; Iacono, W.G.; McGue, M. Father-child transmission of antisocial behavior: The moderating role of father's presence in the home. J. Am. Acad. Child Adolesc. Psychiatry 2008, 47, 406-415.

44. Jaffee, S.R.; Moffitt, T.E.; Caspi, A.; Taylor, A. Life with (or without) father: The benefits of living with two biological parents depend on the father's antisocial behavior. Child Dev. 2003, 74, 109-126.

45. Thornberry, T.P.; Freeman-Gallant, A.; Lovegrove, P.J. The impact of parental stressors on the intergenerational transmission of antisocial behavior. J. Youth Adolesc. 2009, 38, 312-322.

46. Van de Rakt, M. Two Generations of Crime: The Intergenerational Transmission of Criminal Convictions over the Life Course; Ipskamp Drukkers: Nijmegen, The Netherlands, 2011.

47. Eggen, H.; van der Heide, W. Criminaliteit en Rechtshandhaving 2004; WODC/Boom Juridische Uitgevers: Den Haag, The Netherlands, 2005.

48. Ghisletta, P.; Spini, D. An introduction to generalized estimating equations and an application to assess selectivity effects in a longitudinal study on very old individuals. J. Educ. Behav. Stat. 2004, 29, 421-437.

49. Altman, D.G.; Bland, J.M. Interaction revisited: The difference between two estimates. Br. Med. J. 2003, 326, 219, doi:10.1136/bmj.326.7382.219.

50. Statistics Netherlands Statline. Available online: http://statline.cbs.nl/statweb/ (accessed on 28 October 2013).

51. Merz, E.M.; Schulze, H.J. Relatie gescheiden ouders en hun kinderen: Invloed wetswijziging 1998 onderzocht. Demos 2007, 23, 6-8.

52. De Graaf, A. Onder moeders paraplu. Ervaringen van kinderen met relaties na echtscheiding. Demos 2001, 17, 33-37.

(C) 2015 by the authors; licensee MDPI, Basel, Switzerland. This article is an open access article distributed under the terms and conditions of the Creative Commons Attribution license (http://creativecommons.org/licenses/by/4.0/). 